\title{
A classification method for neurogenic heterotopic ossification of the hip
}

\author{
Andreas F. Mavrogenis • Giovanni Guerra • \\ Eric Lodwijk Staals • Giuseppe Bianchi • \\ Pietro Ruggieri
}

Received: 15 June 2011/Accepted: 15 March 2012/Published online: 4 April 2012

(C) The Author(s) 2012. This article is published with open access at Springerlink.com

\begin{abstract}
Background Existing classifications for heterotopic ossification (HO) do not include all $\mathrm{HO}$ types; nor do they consider the anatomy of the involved joint or the neurological injury. Therefore, we performed this study to propose and evaluate a classification according to the location of neurogenic $\mathrm{HO}$ and the neurological injury.

Materials and methods We studied the files of 24 patients/33 hips with brain or spinal cord injury and neurogenic $\mathrm{HO}$ of the hip treated with excision, indomethacin, and radiation therapy. We classified patients according to the Brooker classification scheme as well as ours. Four types of neurogenic $\mathrm{HO}$ were distinguished according to the anatomical location of HO: type 1, anterior; type 2, posterior; type 3, anteromedial; type 4, circumferential. Subtypes of each type were added based on the neurological injury: a, spinal cord; b, brain injury. Mean follow-up was 2.5 years ( $1-8$ years).

Results The Brooker classification scheme was misleading-all hips were class III or IV, corresponding to ankylosis, even though only 14 hips had ankylosis. On the other hand, our classification was straightforward and easy to assign in all cases. It corresponded better to the location of the heterotopic bone, and allowed for preoperative planning of the appropriate surgical approach and evaluation of the prognosis; recurrence of neurogenic $\mathrm{HO}$ was
\end{abstract}

Investigation performed at the Istituto Ortopedico Rizzoli, Bologna, Italy.

A. F. Mavrogenis · G. Guerra - E. L. Staals · G. Bianchi ·

P. Ruggieri $(\bowtie)$

Department of Orthopaedics, Orthopaedic Oncology Service,

Istituto Ortopedico Rizzoli, University of Bologna,

Via Di Barbiano 1/10, 40136 Bologna, Italy

e-mail: pietro.ruggieri@ior.it significantly higher in patients with brain injury (subtype b), while blood loss was higher for patients with anteromedial (type 3) and circumferential (type 4) neurogenic HO.

Conclusions Our proposed classification may improve the management and evaluation of the prognosis for patients with neurogenic HO.

Keywords Neurogenic heterotopic ossification · Hip · Brain injury $\cdot$ Spinal cord injury

\section{Introduction}

Heterotopic ossification (HO) is true osteoblastic activity and abnormal formation of mature lamellar bone within extraskeletal soft tissues where bone does not normally exist [1-5]. HO has been classified according to the clinical setting, location of $\mathrm{HO}$, and progressive or isolated occurrence [1-5] into post-traumatic, nontraumatic or neurogenic, and myositis or fibrodysplasia ossificans progressiva [2-11]. Nontraumatic or neurogenic HO or myositis ossificans circumscripta without trauma is frequent in patients with neurological injury; it occurs in $3.4-47 \%$ of patients after spinal cord injury, $10-20 \%$ of patients after closed head injury, and less often after burns, stroke, brain tumors, sickle cell anemia, hemophilia, tetanus, poliomyelitis, multiple sclerosis, and toxic epidermal necrolysis $[2,7,11]$. The incidence is higher in a spastic extremity, patients with complete spinal cord injuries, prolonged immobilization, a high Glasgow coma score, patients in a long coma, and in those with severe spasticity, deep venous thrombosis, hypercalcemia, and hematomas $[2,8,10,12,13]$. The most frequent site of neurogenic $\mathrm{HO}$ is the hip joint, where it most commonly 
occurs in the flexor (anterior) or adductor (medial) compartments $[2,8,10,11]$.

There are limited data on the evaluation and management of patients with neurogenic HO [2, 11-14]. Several treatments have been proposed, including surgical excision of the heterotopic bone, radiation therapy, physical therapy, and drugs such as nonsteroidal anti-inflammatory drugs and bisphosphonates [15, 16]. However, most of the data derive from studies on post-traumatic $\mathrm{HO}$, most commonly after total hip arthroplasty [17-19], and most treatments have been based on empirical findings [2, 13]. Additionally, classifications of neurogenic $\mathrm{HO}$ are lacking; the classifications that are currently available are related to posttraumatic HO [20-22], and do not address the mechanism of neurological injury or the anatomical compartment involved with the heterotopic bone in order to guide the surgical approach $[2-5,7,8,10,11]$. To address these issues, we performed a clinical study of patients with brain and spinal cord injury and neurogenic $\mathrm{HO}$ of the hip joint, aiming (1) to propose a classification according to the location of $\mathrm{HO}$ at the hip joint and the neurological injury of the patient, and (2) to estimate the prognosis of neurogenic $\mathrm{HO}$ based on this classification with respect to range of motion and clinical ankylosis of the hip joint, blood loss and transfusion requirements, and recurrence of the neurogenic $\mathrm{HO}$ after combined treatment.

\section{Materials and methods}

We retrospectively studied the medical files of 24 patients with neurogenic $\mathrm{HO}$ of the hip joint after central nervous system injury who were diagnosed and treated at the authors' institution from June 2002 to September 2008. There were 17 male and 7 female patients, with a mean age of 38 years (range, 18-63 years). Sixteen patients had neurogenic $\mathrm{HO}$ after brain injury and 8 patients after spinal cord injury; 13 patients were paraplegic, 7 tetraplegic, and 4 hemiplegic. Eighteen of the 24 patients had variable neurogenic $\mathrm{HO}$ of the contralateral hip joint; 9 of the 18 patients (patients 4, 9, 10,12, 15, 18, 19, 21, and 23) also had treatment for neurogenic $\mathrm{HO}$ of the contralateral hip at an interval of 6-12 months. Overall, 24 patients/33 hips were included in this study (Table 1). The mean follow-up was 2.5 years (range, 1-8 years); no patient was lost to follow-up. All patients gave written informed consent to be included in this study. This study was approved by the institutional review board/ethics committee of the authors' institution, and conforms to the latest revision of the Declaration of Helsinki.

Neurogenic HO was classified according to the Brooker classification [1] for post-traumatic HO after total hip arthroplasty (Table 2) as well as the classification proposed herein (Table 3). Our classification is based on the (1) anatomical location of the heterotopic bone as shown in axial computed tomography (CT) scans of the hip and proximal femur, (2) clinical ankylosis of the hip joint, and (3) the etiology of the neurological injury (brain or spinal cord injury). All imaging studies were reviewed by the authors and two radiologists who were asked to classify neurogenic $\mathrm{HO}$ according to these two classifications on a consensus basis.

In all patients, the pre-treatment evaluation included clinical evaluation of the range of motion (flexion, extension, rotation, abduction, and adduction) and ankylosis of the respective hip joint, serial serum alkaline phosphatase measurements and a preoperative measurement of serum hemoglobin, standard radiographs, and at least two threephase technetium-99 $\mathrm{m}(99 \mathrm{mTc})$ methylene diphosphonate bone scans to evaluate the maturation of HO. Treatment was applied at a mean of 1 year (range, 0.5-7 years) after the initial imaging evidence of $\mathrm{HO}$ to allow for the maturation of $\mathrm{HO}$ and facilitate resection with minimum trauma to the surrounding tissue [2]. In all 24 patients/33 hips, treatment included surgical excision of the heterotopic bone followed by radiation therapy in a single fraction of 600 cGy administered within $72 \mathrm{~h}$ postoperatively (range, 48-72 h), and indomethacin administration in daily doses of 50-100 mg starting from the first postoperative day for 6 weeks. Postoperatively, blood transfusion requirements were recorded and serum hemoglobin was measured. Posttreatment evaluation, including clinical examination of range of motion and imaging evaluation of the respective hip joint using radiographs and CT scans, was performed at 6-month intervals to evaluate the effect of treatment and the evidence for recurrence of HO. Recurrent neurogenic HO was defined as a reduction in the range of motion obtained after surgery and imaging evidence of HO.

Statistical analysis was performed using Student's $t$ test and the chi-square test. The data were recorded in a Microsoft ${ }^{\circledR}$ Excel $^{\circledR} 2003$ spreadsheet (Microsoft Corporation, Redmond, WA, USA) and analyzed using MedCalc ${ }^{\circledR}$ software, version 11.1 (MedCalc Software, Mariakerke, Belgium).

\section{Results}

We distinguished four types of neurogenic HO (Fig. 1): type 1 is characterized by anterior (Fig. 2), type 2 by posterior (Fig. 3), type 3 by anteromedial (Fig. 4), and type 4 by circumferential heterotopic bone formation (Fig. 5). A subtype was added to each type according to the etiology of the neurological injury: a, spinal cord injury; b, brain injury (Tables 1, 3). In all patients/hips, the classification proposed herein was straightforward and easy to assign. 


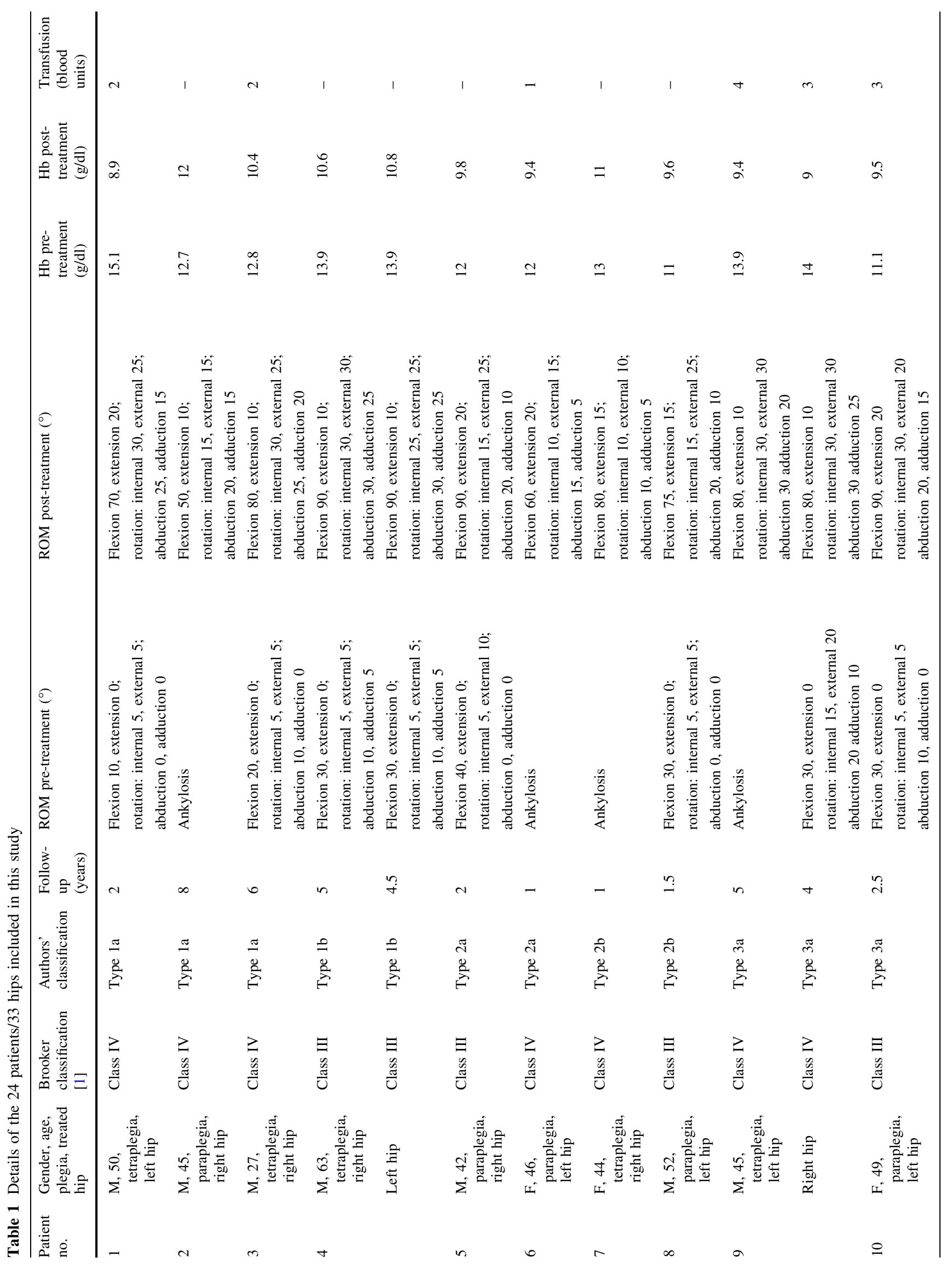




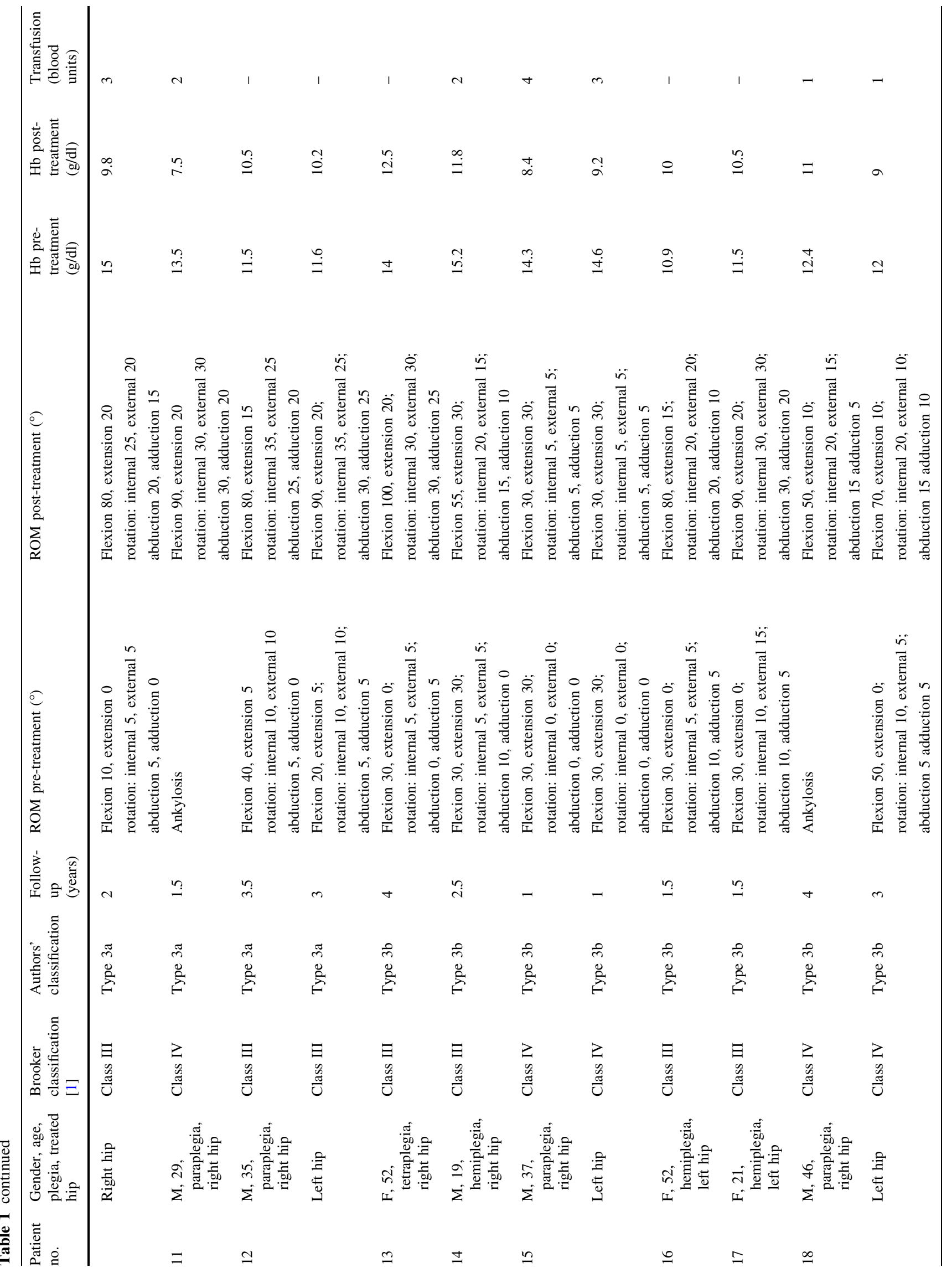




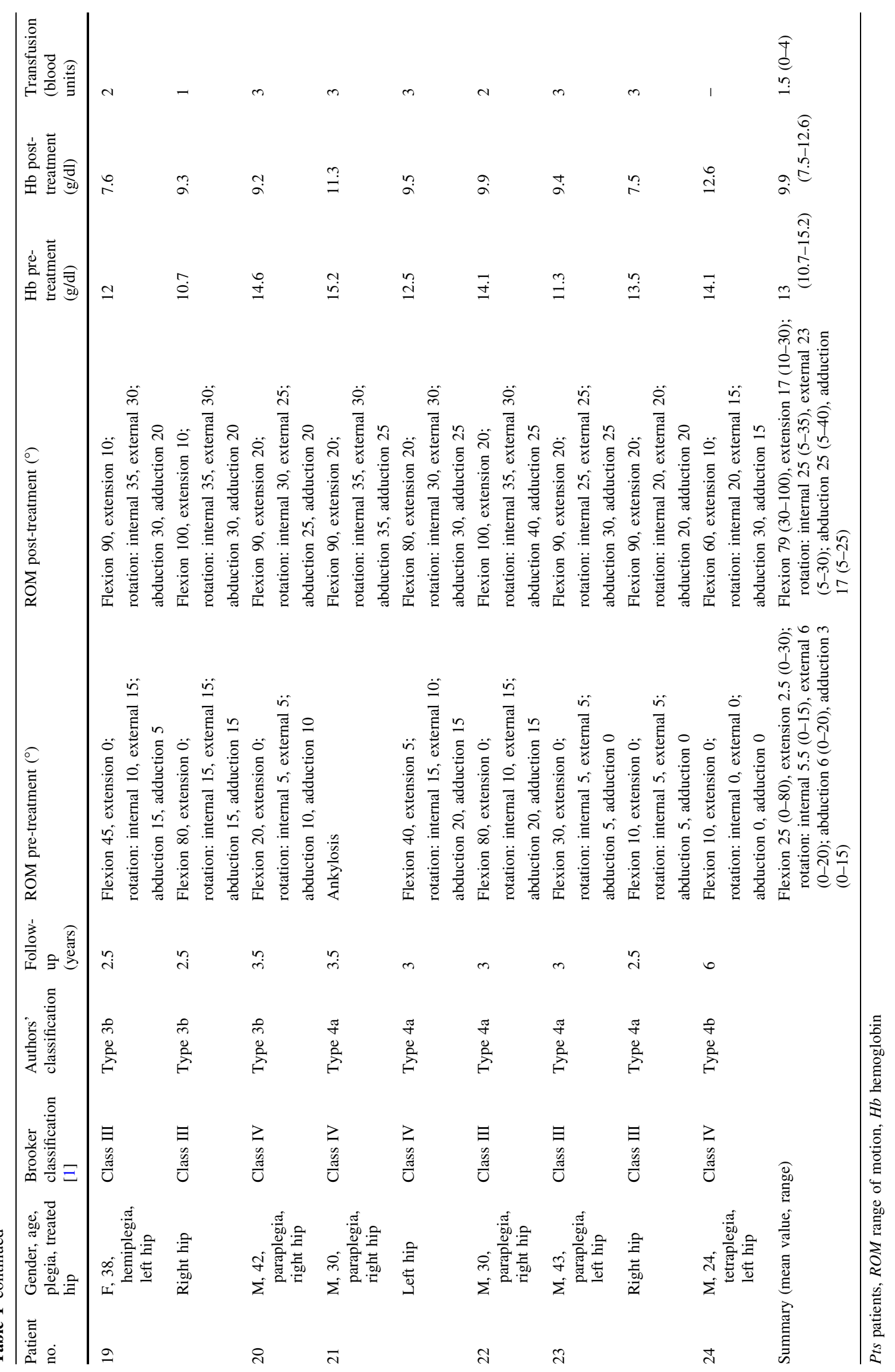


Table 2 Brooker classification of HO of the hip

\begin{tabular}{|c|c|c|}
\hline Class & $\begin{array}{l}\text { Patients } \\
(n=24) / \text { hips } \\
(n=33)\end{array}$ & Description \\
\hline I & - & $\begin{array}{l}\text { Bone islands within soft tissues } \\
\text { about the hip }\end{array}$ \\
\hline II & - & $\begin{array}{l}\text { Bone spurs in pelvis or proximal end of } \\
\text { femur, leaving at least } 1 \mathrm{~cm} \text { between the } \\
\text { opposing bone surfaces }\end{array}$ \\
\hline III & $12 / 17$ & $\begin{array}{l}\text { Bone spurs that extend from the pelvis or } \\
\text { the proximal end of the femur, which } \\
\text { reduce the space between the opposing } \\
\text { bone surfaces to less than } 1 \mathrm{~cm}\end{array}$ \\
\hline IV & $12 / 16$ & Radiographic ankylosis of the hip \\
\hline
\end{tabular}

Table 3 Authors' classification of neurogenic HO of the hip

\begin{tabular}{lll}
\hline Type & Patients & Description \\
& $(n=24) / h i p s$ & \\
& $(n=33)$ & \\
\end{tabular}

Type 1

$\begin{array}{ll}\text { a: Spinal cord injury } & 3 / 3 \\ \text { b: Brain injury } & 1 / 2\end{array}$

Type 2

$\begin{array}{ll}\text { a: Spinal cord injury } & 2 / 2 \\ \text { b: Brain injury } & 2 / 2\end{array}$

Type 3
a: Spinal cord injury $4 / 7$
b: Brain injury
$8 / 11$

Type 4

$\begin{array}{llc}\text { a: Spinal cord injury } & 3 / 5 & \begin{array}{c}\text { Neurogenic HO around the } \\ \text { hip (circumferential), } \\ \text { b: Brain injury }\end{array} \\ \end{array}$

Preoperative planning facilitated the surgical excision of the heterotopic bone by choosing the appropriate surgical approach according to the anatomical location (type) of neurogenic HO; the anterior approach to the hip was used for anterior and anteromedial neurogenic $\mathrm{HO}$ (types 1 and 3 ), the posterior approach for posterior neurogenic $\mathrm{HO}$ (type 2), and a single-stage combined anterior and posterior approach for circumferential neurogenic HO (type 4).

Pre-treatment clinical examination showed a reduction in the range of motion and an inability to achieve a standing position in all patients, an inability to achieve a sitting position in 22 patients, hip ankylosis in 7 patients/14

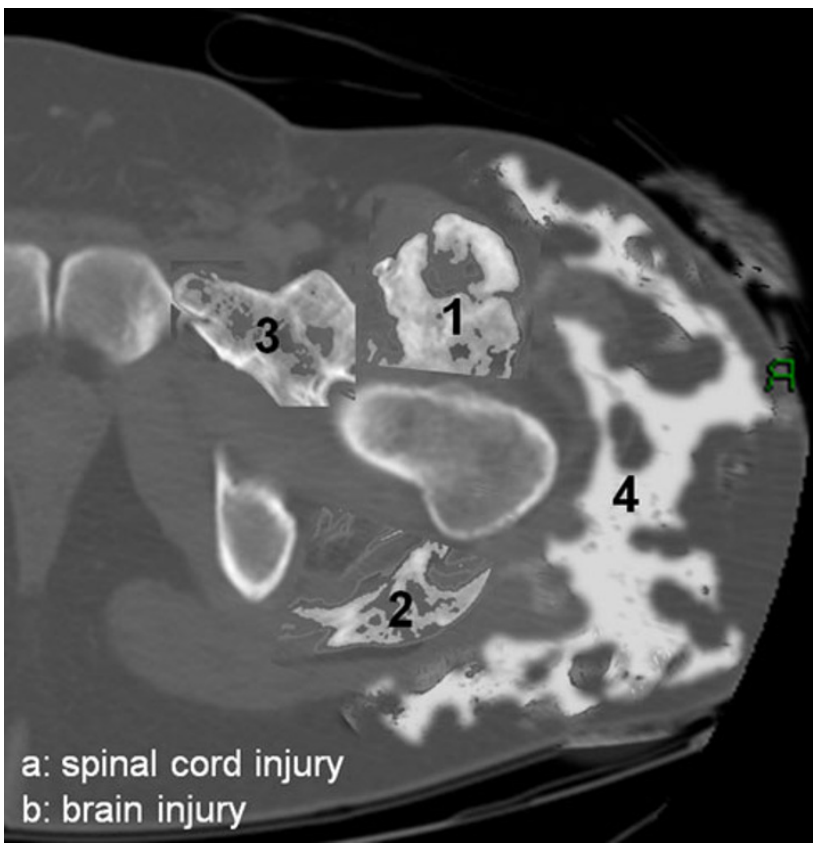

Fig. 1 A classification method for neurogenic HO of the hip according to the anatomical location of HO (types 1-4) and the neurological injury (subtypes $a$ and $b$ )

hips, and hip pain in 1 patient (patient 1). According to the Brooker classification [1], all patients/hips were classified as class III or IV, which corresponds to hip ankylosis; however, only 7 patients/14 hips presented clinical or imaging evidence of ankylosis (Table 1). The mean hip flexion before treatment was $25^{\circ}$ (range, $0-80^{\circ}$ ), extension $2.5^{\circ}$ (range, $0-30^{\circ}$ ), internal rotation $5.5^{\circ}$ (range, $0-10^{\circ}$ ), external rotation $6^{\circ}$ (range, $0-20^{\circ}$ ), abduction $6^{\circ}$ (range, $0-20^{\circ}$ ), and adduction $3^{\circ}$ (range, $0-15^{\circ}$ ). After treatment, no patient had ankylosis of the hip joint, all patients were able to sit, and the mean range of hip motion significantly improved ( $p=0.001)$; the mean hip flexion after treatment was $79^{\circ}\left(\right.$ range, $\left.30-100^{\circ}\right)$, extension $17^{\circ}$ (range, 10-30 ${ }^{\circ}$ ), internal rotation $25^{\circ}$ (range, 5-35 $5^{\circ}$, external rotation $23^{\circ}$ (range, 5-30 $0^{\circ}$, abduction $25^{\circ}$ (range, 5-40 ), and adduction $17^{\circ}$ (range, 5-25 ). Improvement was statistically significant for all motions (flexion, $p=0.035$; extension, $p=0.030$; internal rotation, $p=0.020$; external rotation, $p=0.030$; abduction, $p=0.030$; adduction, $p=0.020)$, regardless of the type of neurogenic HO $(p=0.460)$.

Our classification also allowed for the estimation of blood loss,transfusion requirements, and recurrence of neurogenic HO. Overall, blood transfusion was necessary in 14 patients/20 hip operations. Although blood loss can be related to many factors, blood loss and transfusion requirements were statistically significantly higher in patients with type 3 and 4 compared to patients with type 1 and 2 neurogenic $\mathrm{HO}$ (chi-square test, $p=0.040$ ). Overall, clinical and imaging recurrence of neurogenic $\mathrm{HO}$ was 


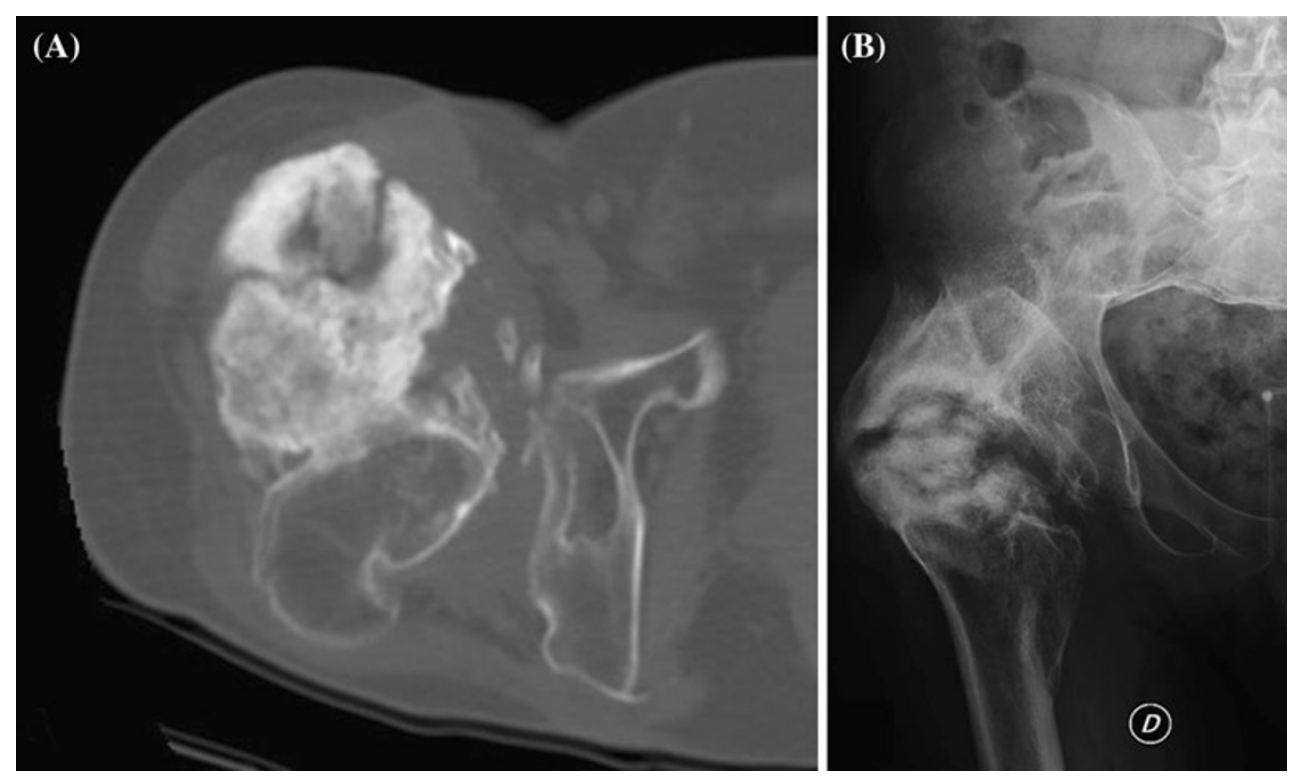

Fig. 2 a Axial computed tomography scan and $\mathbf{b}$ anteroposterior radiograph of the right hip of a 63-year-old man with anterior neurogenic HO of the hip after closed brain injury (patient 4 ; type $1 \mathrm{~b}$ )
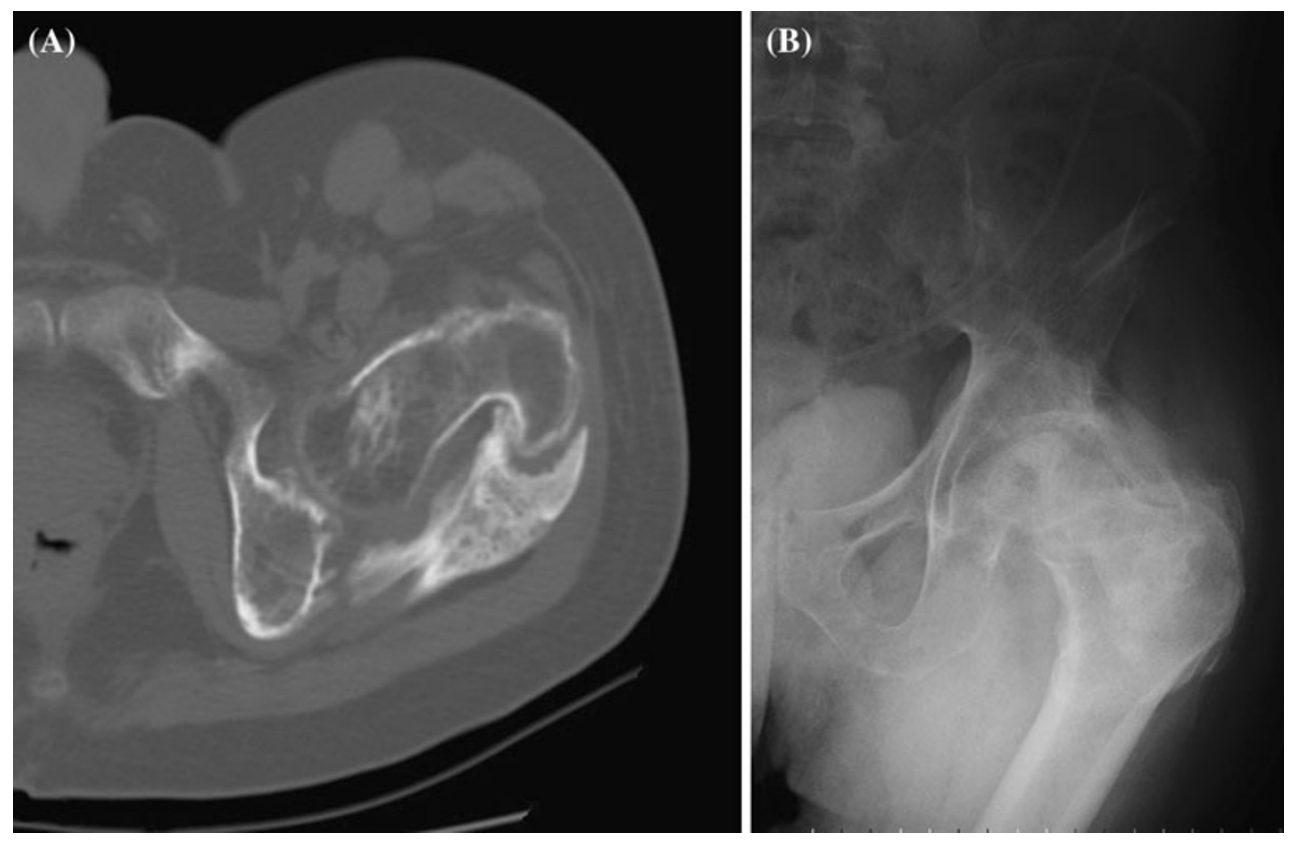

Fig. 3 a Axial computed tomography scan and $\mathbf{b}$ anteroposterior radiograph of the left hip of a 52-year-old man with posterior neurogenic HO of the hip after closed brain injury (patient 8 ; type $2 b$ )

observed at 2 years in 5 patients/7 hips [21\%; patients 4 , 6, 7 (bilateral), 10 (bilateral), and 17]; there were 4 patients/6 hips with neurogenic $\mathrm{HO}$ after brain injury (subtype b), and 1 patient/hip after spinal cord injury (subtype a). Recurrence of neurogenic $\mathrm{HO}$ was statistically significantly higher in patients with brain injury (Student's $t$ test, $p=0.040$ ). Although recurrence was higher in patients with type 3 neurogenic HO, a statistically significant difference between the anatomical location of neurogenic HO and recurrence was not observed (Student's $t$ test, $p=0.198)$.

\section{Discussion}

Neurogenic $\mathrm{HO}$ is a frequent complication in patients with central nervous system injury, and a potential cause of increased morbidity from complications resulting from 

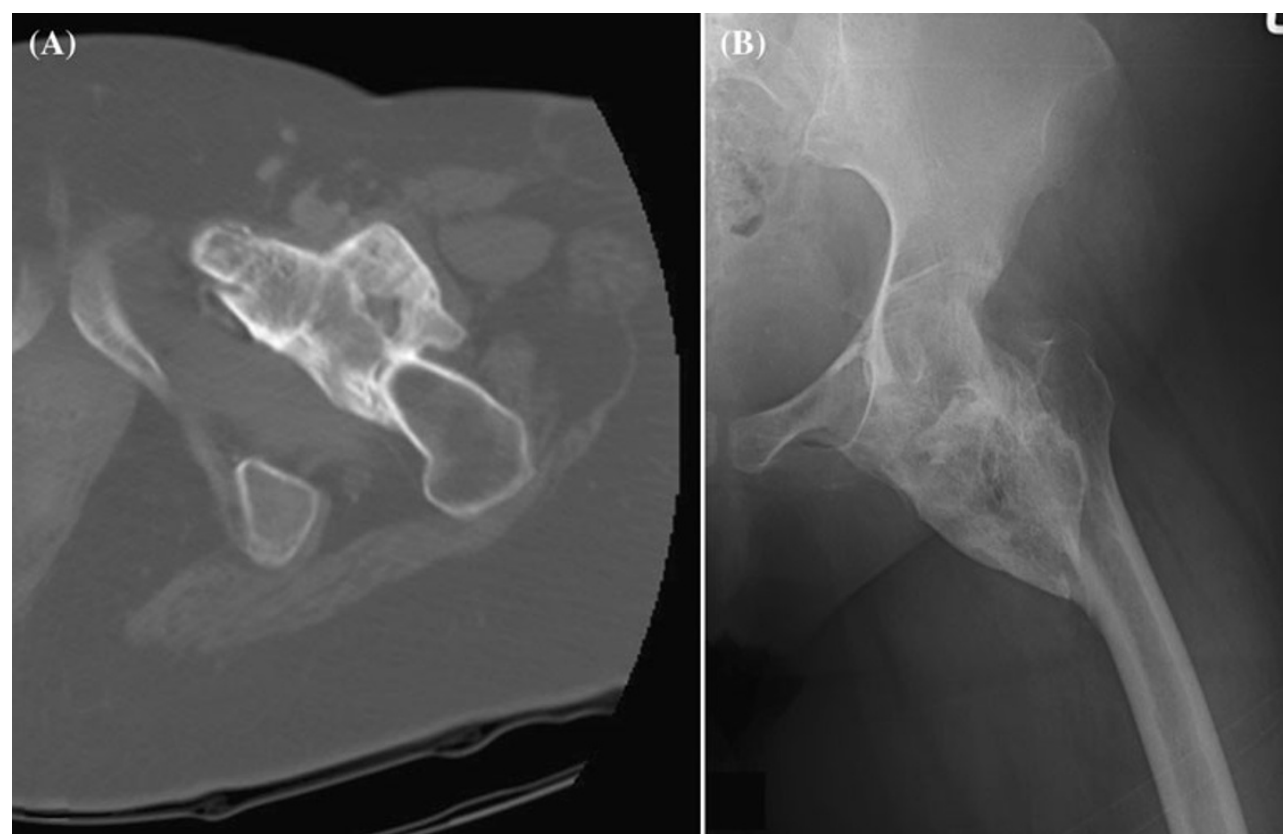

Fig. 4 a Axial computed tomography scan and b anteroposterior radiograph of the left hip of a 49-year-old woman with anteromedial neurogenic $\mathrm{HO}$ of the hip after spinal cord injury (patient 10; type 3a)
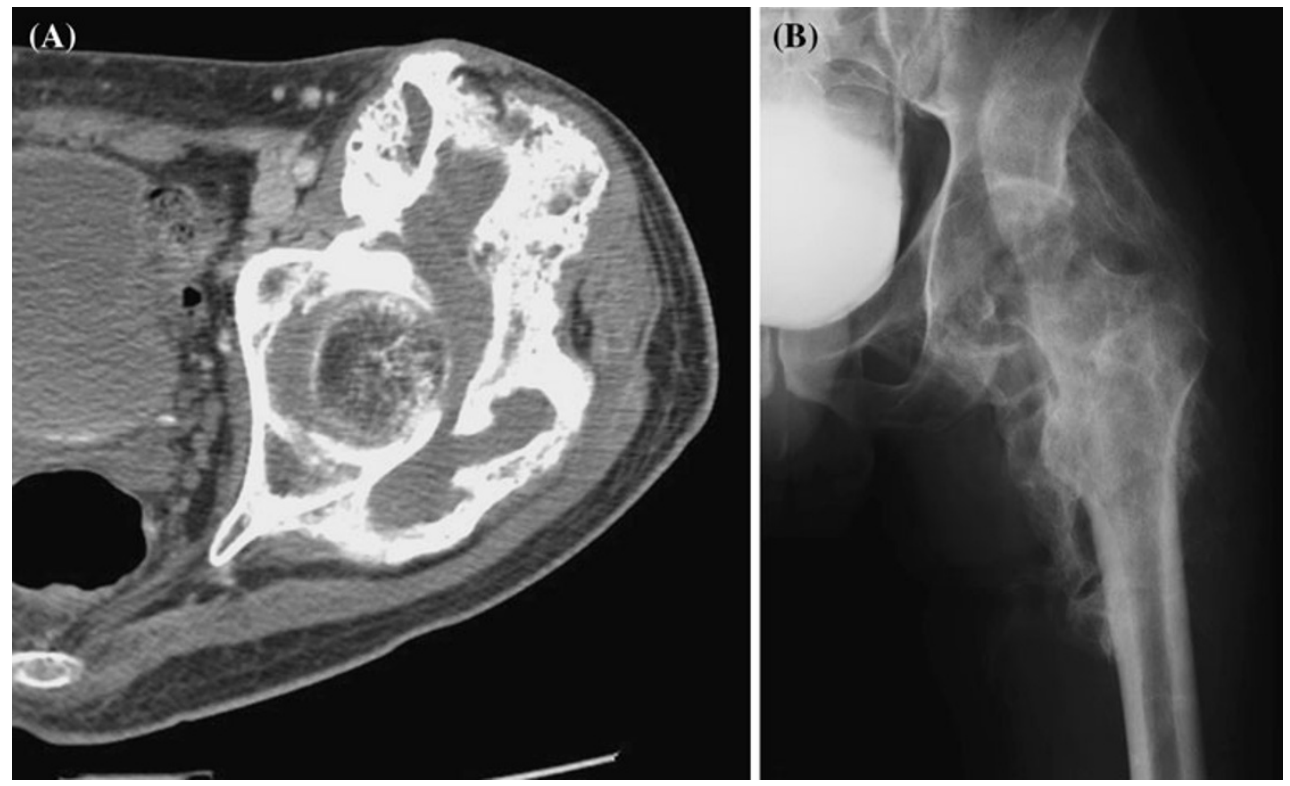

Fig. 5 a Axial computed tomography scan and $\mathbf{b}$ anteroposterior radiograph of the left hip of a 43-year-old man with circumferential neurogenic HO around the hip after spinal cord injury (patient 23; type 4a)

immobilization [2, 11-14, 16, 23]. However, neurogenic $\mathrm{HO}$ is less well studied than the other HO types, and classifications for neurogenic HO are lacking [2, 11-14]; most of the data reported relate to patients with post-traumatic HO after total hip arthroplasty [17-19]. Therefore, we performed this study to propose a classification for neurogenic $\mathrm{HO}$, to compare that classification with the Brooker classification [1], and to validate this classification in a clinical series of patients treated with combined surgical excision, indomethacin, and postoperative radiation therapy. The classification proposed herein distinguishes 4 types of neurogenic HO (types 1-4) according to the location of heterotopic bone formation around the hip joint, and 2 subtypes ( $\mathrm{a}$ and $\mathrm{b}$ ) according to the etiology of the neurological injury. Our results showed that the present classification can be useful for the management of neurogenic HO patients. It provides for preoperative planning of the surgical approach according to the anatomical location 
of the neurogenic $\mathrm{HO}$, and permits an estimation of the prognosis regarding blood loss, transfusion requirements, and recurrence of the neurogenic HO.

We see four limitations in this study. First, the sample size is small; however, the lack of a classification for the specific HO type supports this study. Second, we did not use three-dimensional CT scan for the preoperative evaluation of HO. In this series and our practice, we use CT scan for the preoperative evaluation of $\mathrm{HO}$ patients, and axial CT scan views to classify HO and to indicate areas that should be avoided or carefully removed at surgery. Computed tomography scans may identify a low-density material in the soft tissue adjacent to areas of ectopic ossification that are postulated to be immature unossified connective tissue, the violation of which may be responsible for the serious intraoperative bleeding frequently experienced during the resection of HO [11]. Compared to three-dimensional CT reconstruction, axial CT scan is widely available and more easily read in clinical practice by most surgeons; also, in our opinion, it provides all of the information needed for preoperative planning. Third, we did not perform a volumetric quantification of the heterotopic bone, and did not include this volume in our classification criteria. We based our classification on the anatomical compartment involved by the neurogenic $\mathrm{HO}$ and not on its volume because we believe that the volume of $\mathrm{HO}$ is only related to the reduction in the range of motion or ankylosis and ease of surgical excision, not to the choice of surgical approach or the outcome of neurogenic HO. Moreover, including the volume of $\mathrm{HO}$ as a criterion would have made the classification more complex. Fourth, blood loss from surgical excision of the heterotopic bone can be related to many factors, and is not validated for this study's purpose. However, we measured blood loss and transfusion requirements in order to provide a prognostic factor for the surgical treatment of each type of neurogenic HO.

A classification should meet certain criteria to be valuable and widely accepted. These should include ease of understanding, an ability to be easily recalled, consideration of the anatomy, an understanding of the mechanism of injury, the proposal of therapeutic guidelines according to the specific types, and the provision of useful information regarding the prognosis of the various types. We believe that the classification proposed herein addresses all of the above. The advantages of the Brooker classification are that it is based solely upon anteroposterior radiographs of the hip, and so it is a relatively simple and valid measurement that appears to correlate well with the clinical picture of overall hip function [24]. However, it does not address the anatomical compartment involved by $\mathrm{HO}$, and does not correlate with the extent of HO into anatomical compartments, it cannot guide the surgical treatment or estimate prognosis, and it does not consider the etiology of the neurological injury that led to HO. Other methods have also been reported for the classification of $\mathrm{HO}$ in patients with post-traumatic $\mathrm{HO}$ and $\mathrm{HO}$ following hip arthroplasty [20-22]. These methods were based on the anteroposterior radiographic view of the hip, and classified $\mathrm{HO}$ according to the location around the femoral neck, without detailed anatomical localization. Some authors attempted to classify a central and lateral $\mathrm{HO}$ with respect to an imaginary borderline from the greater trochanter to the lateral edge of the acetabulum [25], or to divide the space around the femoral neck into thirds (central, lateral and medial) [26]; these classifications have not been widely accepted because of the complexity and difficulty involved in classifying $\mathrm{HO}$ into nonanatomical (imaginary) areas around the hip joint.

In the present classification, we distinguished 4 types (types 1-4) of neurogenic HO based on the anatomical compartments involved by the heterotopic bone. Since the etiology of neurogenic $\mathrm{HO}$ was found to be a statistically significant predictor for recurrence of $\mathrm{HO}$, we added 2 subtypes (subtypes a and b) based on the etiology of neurological injury. The use of this classification made preoperative planning of the appropriate surgical approach rather straightforward. In the most common cases with anterior and/or medial HO (types 1 and 3), the anterior approach to the hip should be used; in cases of posterior HO (type 2), the posterior approach to the hip should be used; and in cases of circumferential HO (type 4), a combined anterior and lateral approach is recommended. Post-treatment improvement in the range of motion of the hip was significant in all cases, regardless of the type of neurogenic HO; therefore, the presence of ankylosis was not included in the criteria of our classification-it was only recorded to evaluate the effect of treatment. Additionally, HO that appears to be bridging according to the Brooker classification may actually be located either anterior or posterior to the hip, and thus may not cause significant loss of range of motion [21, 22]. This was also observed in the present clinical series; although according to the Brooker classification all of the patients/hips were classified as class III or IV, meaning hip ankylosis, clinical and imaging evidence of ankylosis was observed in only 7 patients/14 hips. The location (type) of neurogenic HO may also provide an estimate of blood loss and transfusion requirements. In the present study, blood loss and transfusion requirements were higher for patients with anteromedial (type 3) and circumferential (type 4) neurogenic HO. This may be explained by the fact that anteromedial or circumferential lesions and lesions in proximity to major vessels are more difficult to excise. A classification should also address the prognosis of a disease. Recurrence rates of neurogenic HO ranging from 17 to $58 \%$ have been reported $[10,11,13,27]$. In the present study, the 
recurrence rate of neurogenic $\mathrm{HO}$ was $21 \%$ (5 patients/7 hips) at 2 years. The etiology of the neurological injury was found to be a significant prognostic factor for recurrence; recurrence was 6 times more common after brain injury (subtype b) compared to spinal cord injury (subtype a). We explain this by the fact that spinal cord injury patients may have a better performance status and selective motor control in the extremity, and can more easily achieve a better functional outcome [27-29]. The anatomical location of neurogenic $\mathrm{HO}$ was not found to be a significant prognostic factor for recurrence.

In conclusion, the management of neurogenic $\mathrm{HO}$ patients is challenging. A new classification specifically designed for this disorder is necessary. Since the trauma of surgery may actually aggravate the condition, adequate classification, preoperative planning, and combined treatment are beneficial.

Conflict of interest No benefits have been or will be received from a commercial party related directed or indirectly to the subject matter of this article.

Open Access This article is distributed under the terms of the Creative Commons Attribution License which permits any use, distribution, and reproduction in any medium, provided the original author(s) and the source are credited.

\section{References}

1. Brooker AF, Bowerman JW, Robinson RA, Riley LH Jr (1973) Ectopic ossification following total hip replacement: incidence and a method of classification. $J$ Bone Joint Surg Am 55:1629-1632

2. Garland DE (1991) A clinical perspective on common forms of acquired heterotopic ossification. Clin Orthop Relat Res 263:13-29

3. Naraghi FF, DeCoster TA, Moneim MS, Miller RA, Rivero D (1996) Heterotopic ossification. Orthopedics 19:145-151

4. Reardon MJ, Tillou A, Mody DR, Reardon PR (1997) Heterotopic calcification in abdominal wounds. Am J Surg 173:145-147

5. Thomas BJ (1992) Heterotopic bone formation after total hip arthroplasty. Orthop Clin North Am 23:347-358

6. Benetos IS, Mavrogenis AF, Themistocleous GS, Kanellopoulos AD, Papagelopoulos PJ, Soucacos PN (2006) Optimal treatment of fibrodysplasia ossificans progressiva with surgical excision of heterotopic bone, indomethacin, and irradiation. J Surg Orthop Adv 15(2):99-104

7. Gibson CJ, Poduri KR (1997) Heterotopic ossification as a complication of toxic epidermal necrolysis. Arch Phys Med Rehabil 78:774-776

8. Inan M, Chan G, Dabney K, Miller F (2006) Heterotopic ossification following hip osteotomies in cerebral palsy: incidence and risk factors. J Pediatr Orthop 26:551-556

9. Randelli F, Pierannunzii L, Banci L, Ragone V, Aliprandi A, Buly R (2010) Heterotopic ossifications after arthroscopic management of femoroacetabular impingement: the role of NSAID prophylaxis. J Orthop Traumatol 11(4):245-250

10. Stover SL, Niemann KM, Tulloss JR (1991) Experience with surgical resection of heterotopic bone in spinal cord injury patients. Clin Orthop Relat Res 263:71-77
11. Subbarao JV, Garrison SJ (1999) Heterotopic ossification: diagnosis and management, current concepts and controversies. J Spinal Cord Med 22(4):273-283

12. McCarthy EF, Sundaram M (2005) Heterotopic ossification: a review. Skeletal Radiol 34:609-619

13. Simonsen LL, Sonne-Holm S, Krasheninnikoff M, Engberg AW (2007) Symptomatic heterotopic ossification after very severe traumatic brain injury in 114 patients: incidence and risk factors. Injury 38:1146-1150

14. Balboni TA, Gobezie R, Mamon HJ (2006) Heterotopic ossification: pathophysiology, clinical features and the role of radiotherapy for prophylaxis. Int J Rad Oncol Biol Phys 65(5):1289-1299

15. Garland DE, Alday B, Venos KG, Vogt JC (1983) Diphosphonate treatment for heterotopic ossifications in spinal cord injury patients. Clin Orthop Relat Res 176:197-200

16. Ippolito E, Formisano R, Caterini R, Farsetti P, Penta F (1999) Operative treatment of heterotopic ossification in patients with coma after brain injury. Clin Orthop Relat Res 365:130-138

17. Banovac K, Williams JM, Patrick LD, Haniff YM (2001) Prevention of heterotopic ossification after spinal cord injury with indomethacin. Spinal Cord 39:370-374

18. Gregoritch SJ, Chadha M, Pelligrini VD, Rubin P, Kantorowitz DA (1994) Randomized trial comparing preoperative versus postoperative irradiation for prevention of heterotopic ossification following prosthetic total hip replacement: preliminary results. Int J Radiat Oncol Biol Phys 30:55-62

19. Seegenschmiedt MH, Keilholz L, Martus P (1997) Prevention of heterotopic ossification about the hip: final results of two randomized trials in 410 patients using either preoperative or postoperative radiation therapy. Int $\mathrm{J}$ Radiat Oncol Biol Phys 39:161-171

20. Arcq M (1988) Zur Problematik der periartikuliren Verkncherungen nach Htiftendoprothese. In: Maaz B, Gierse H (eds) Aktueller Stand der zementfreien Hiftendoprothetik. 2. Kaiserwerther Symposium. Thieme, Stuttgart, pp 71-84

21. Schmidt J, Hackenbroch MH (1996) A new classification for heterotopic ossifications in total hip arthroplasty considering the surgical approach. Arch Orthop Trauma Surg 115(6):339-343

22. Schuh A, Zeiler G (2005) The modified Brooker classification for evaluation of heterotopic ossifications in total hip replacement. Zentralbl Chir 130(4):293-296

23. Van Kuijk AA, Geurts AC, van Kuppevelt HJ (2002) Neurogenic heterotopic ossification in spinal cord injury. Spinal Cord 40:313-326

24. Wright JG, Moran E, Bogoch E (1994) Reliability and validity of the grading of heterotopic ossification. J Arthroplasty 9(5):549-553

25. Kjaersgaard-Andersen P, Sletgård J, Gjerløff C, Lund F (1990) Heterotopic bone formation after noncemented total hip arthroplasty. Location of ectopic bone and the influence of postoperative antiinflammatory treatment. Clin Orthop Relat Res 252:156-162

26. Orzel JA, Rudd TG (1985) Heterotopic bone formation: clinical, laboratory and imaging correlation. J Nucl Med 26:125-132

27. Kaplan FS, Glaser DL, Hebela N, Shore EM (2004) Heterotopic ossification. J Am Acad Orthop Surg 12:116-125

28. Hastings H 2nd, Graham TJ (1994) The classification and treatment of heterotopic ossification about the elbow and forearm. Hand Clin 10(3):417-437

29. Ring D, Jupiter JB (2003) Operative release of complete ankylosis of the elbow due to heterotopic bone in patients without severe injury of the central nervous system. J Bone Joint Surg Am $85 \mathrm{~A}(5): 849-857$ 